\title{
Influence of the invasive Asian clam Corbicula fluminea (Bivalvia: Corbiculidae) on estuarine epibenthic assemblages
}

\author{
M.I. Ilarri ${ }^{\mathrm{a}, \mathrm{b}, *}$, A.T. Souza ${ }^{\mathrm{a}}$, C. Antunes ${ }^{\mathrm{a}, \mathrm{c}, \mathrm{d}}$, L. Guilhermino ${ }^{\mathrm{a}, \mathrm{b}}$, R. Sousa ${ }^{\mathrm{a}, \mathrm{e}}$ \\ a Interdisciplinary Centre of Marine and Environmental Research (CIMAR/CIMAR), University of Porto, Rua dos Bragas 289, P 4050-123 Porto, Portugal \\ ${ }^{\mathrm{b}}$ ICBAS - Instituto de Ciências Biomédicas de Abel Salazar, Universidade do Porto, Rua de Jorge Viterbo Ferreira, 228, 4050-313 Porto, Portugal \\ ${ }^{\mathrm{c}}$ Aquamuseu do Rio Minho, Parque do Castelinho, 4920-290 Vila Nova de Cerveira, Portugal \\ 'University School Gallaecia, Largo das Oliveiras, 4920 Vila Nova de Cerveira, Portugal \\ e CBMA - Centre of Molecular and Environmental Biology, Department of Biology, University of Minho, Campos de Gualtar, 4710-057 Braga, Portugal
}

\section{A R T I C L E I N F O}

\section{Article history:}

Received 8 August 2013

Accepted 15 March 2014

Available online 24 March 2014

\section{Keywords:}

Carcinus maenas

Crangon crangon

Pomatoschistus microps

invasive alien species

Minho estuary

predation

\begin{abstract}
A B S T R A C T
One of the most widespread invasive alien species (IAS) in aquatic ecosystems is the Asian clam Corbicula fluminea. Several studies have shown that $C$. fluminea can cause large-scale changes in macrozoobenthic assemblages; however, very few attempted to investigate the effects of this IAS on mobile epibenthic species, such as fishes and crustaceans. In this context, the influence of $C$. fluminea on epibenthic species was investigated during one year by comparing the associated epibenthic fauna in three nearby sites of the Minho estuary (NW of the Iberian Peninsula), wherein the abiotic conditions are similar but the density of the Asian clam is highly different. From a total of 13 species, six were significantly influenced by C. fluminea; five responded positively, namely the brown shrimp Crangon crangon, the European eel Anguilla anguilla, the common goby Pomatoschistus microps, the brown trout Salmo trutta fario and the great pipefish Syngnathus acus, whereas the shore crab Carcinus maenas was negatively influenced. However, stomach contents analysis revealed that fish and crustacean species do not feed on C. fluminea, suggesting that this IAS is still not a large component of the diet of higher trophic levels in this estuarine ecosystem. Our results suggest that the structure provided by $C$. fluminea shells is likely to be one of the main factors responsible for the differences observed. C. fluminea physical structure seems to influence the epibenthic associated fauna, when found in densities higher than 1000 ind. $/ \mathrm{m}^{2}$, with sedentary small-bodied crustaceans and fishes being mainly attracted by the increasing in habitat complexity and consequent enhancement of heterogeneity and shelter availability.
\end{abstract}

(c) 2014 Elsevier Ltd. All rights reserved.

\section{Introduction}

Invasive alien species (IAS) are one of the most significant threats affecting the integrity of aquatic ecosystems (Richter et al., 1997; Grosholz, 2002). In recent years, aquatic ecosystems have been subjected to numerous introductions which contributed for significant changes in structure and functioning of the invaded systems (Byrnes et al., 2007; Strayer, 2010). Via physico-chemical (e.g. light availability, nutrient levels, heat transfer, habitat complexity and physical transport of materials) and biological (e.g. diversity, spatial distribution, biotic interactions affecting the density and biomass of other species) changes, IAS can be responsible for impacts ranging

\footnotetext{
* Corresponding author. ICBAS - Instituto de Ciências Biomédicas de Abel Salazar, Universidade do Porto, Rua de Jorge Viterbo Ferreira, 228, 4050-313 Porto, Portugal.

E-mail address: martinailarri@gmail.com (M.I. Ilarri).
}

from the individual to the ecosystem level (Sousa et al., 2011; Simberloff et al., 2013). However, due to the high context dependency, it is difficult to predict the potential impacts of IAS in a new environment. The potential impacts of IAS, in part, can be related to the complex organism-organism and organism-habitat interactions, as well as the impacts of a particular species which can vary across different geographic locations (Mayer et al., 2000; Ricciardi and Atkinson, 2004; Ward and Ricciardi, 2007).

The structural complexity created by some IAS can directly or indirectly modify communities and ecosystems, given that invasive species have the capacity to modulate the availability of resources to other species, by physically creating, modifying and maintaining habitats (i.e. physical ecosystem engineering; Crooks, 2002). Bivalves are one of the most invasive faunal groups in aquatic ecosystems and their engineering attributes can markedly affect biological communities, ecosystem processes and functions (Sousa et al., 2009, in press). The hardness of their shells plays an 
important role in bivalve ecological success, once it can preclude the access of predators (Wright et al., 2012). Indeed, it can also contribute to important physical modifications (i.e. provision of substrata for attachment, provision of shelter from predators, physical and/or physiological stress, affecting also the transport of particles and solutes in the benthic environment; Gutiérrez et al., 2003) that can greatly influence the associated fauna (Werner and Rothhaupt, 2007; Zaiko et al., 2009; Ilarri et al., 2012).

Currently, one of the most widespread IAS in aquatic ecosystems is the Asian clam Corbicula fluminea (Sousa et al., 2008d). It was first recorded in Europe at least in the early 1980s (Mouthon, 1981), and now it occurs in almost all European countries (Ilarri and Sousa, 2012). In Portugal, C. fluminea was firstly reported in the early 1980's (Mouthon, 1981), presently occurs in most Portuguese hydrological basins, including many estuarine systems (Sousa et al., 2007a). Since 2004, studies focusing on C. fluminea ecology were intensified in the Minho River (NW of the Iberian Peninsula). Most of these studies further confirmed the high invasive potential of the species, showing that $C$. fluminea dominates the infauna community in terms of density, biomass, and secondary production in the last $70 \mathrm{~km}$ of the Minho River (Sousa et al., 2007b, 2008a,b,c). Also, C. fluminea can influence the habitat heterogeneity, by modifying the diversity of the macrozoobenthic assemblages favoring sessile crustaceans, gastropods and insects and negatively affecting other bivalve species (Ilarri et al., 2012). However, nothing is known about the influence of $C$. fluminea on mobile epibenthic species. In this context, our aims were threefold: (a) to examine whether different densities of $C$. fluminea influence the epibenthic assemblages, (b) to investigate possible seasonal changes in the epibenthic assemblages responding to different $C$. fluminea densities, and (c) to examine through stomach content analysis whether the epibenthic species prey on $C$. fluminea.

\section{Materials and methods}

\subsection{Study area and sampling campaign}

The Minho estuary (NW Iberian Peninsula) has a maximum length of $40 \mathrm{~km}$ and covers an area of approx. $23 \mathrm{~km}^{2}$ (Sousa et al., 2007b). Detailed description of the macrozoobenthic assemblages and main abiotic characteristics of this area can be found in previous studies (Sousa et al., 2005, 2008c). The present study was performed in three selected sites at the lower estuary (situated about $8 \mathrm{~km}$ from the river mouth)(Fig. 1). The selected sites are near to each other, with the site 1 (S1) located about $400 \mathrm{~m}$ away from site 2 (S2) and about $800 \mathrm{~m}$ away from site 3 (S3). The selected study area presents an annual average depth that ranged between 2.0 and $2.5 \mathrm{~m}$ and the Minho estuary is classified as a mesotidal and partially mixed system (Ferreira et al., 2003), although during periods of high river discharge, it tends towards a salt wedge estuary (Sousa et al., 2005). The water current varied from moderate to strong and these variations are due to the tidal influence or to upstream river discharge (Ferreira et al., 2003). The substratum is composed mainly by sandy sediments, debris, leaf litter and Corbicula fluminea shells (live and dead).

In order to characterized the epibenthic assemblages, tows were performed and fyke-nets were placed during an annual cycle (four seasons), from January to November. Four replicate tows per site in each of the four seasons (total of 48 samples) were performed always during the day at high tide using a beam trawl $(5 \mathrm{~mm}$ mesh size) towed at constant speed $\left(2 \mathrm{~km} \mathrm{~h}^{-1}\right)$ for $90 \mathrm{~s}$, corresponding to a total distance of $50 \mathrm{~m}$ (Freitas et al., 2009). Whereas, for the fykenets ( $10 \mathrm{~mm}$ mesh, $0.7 \mathrm{~m}$ diameter mouth, $7 \mathrm{~m}$ long, $3.5 \mathrm{~m}$ central wing) six replicates per site in each of the four seasons were collected (total of 72 samples). Fyke-nets remained underwater for $24 \mathrm{~h}$. All individuals caught for both tows and fyke-nets were counted and measured to the nearest $0.1 \mathrm{~mm}$.

At each site, during low tides, environmental variables (water temperature, salinity, $\mathrm{pH}$, dissolved oxygen (DO) and redox potential (ORP)) were also measured with a multiparameter probe YSI 6820.

Gut contents of the fishes and crustaceans sampled by fyke-nets, in the three selected sites, were analyzed using a stereomicroscope, in order to check whether these species had parts and/or traces of Corbicula fluminea in their digestive tracts.

\subsection{Data analysis}

Analysis of similarities (ANOSIM) was performed to explore the abiotic data patterns over space and time. Initially, all variables

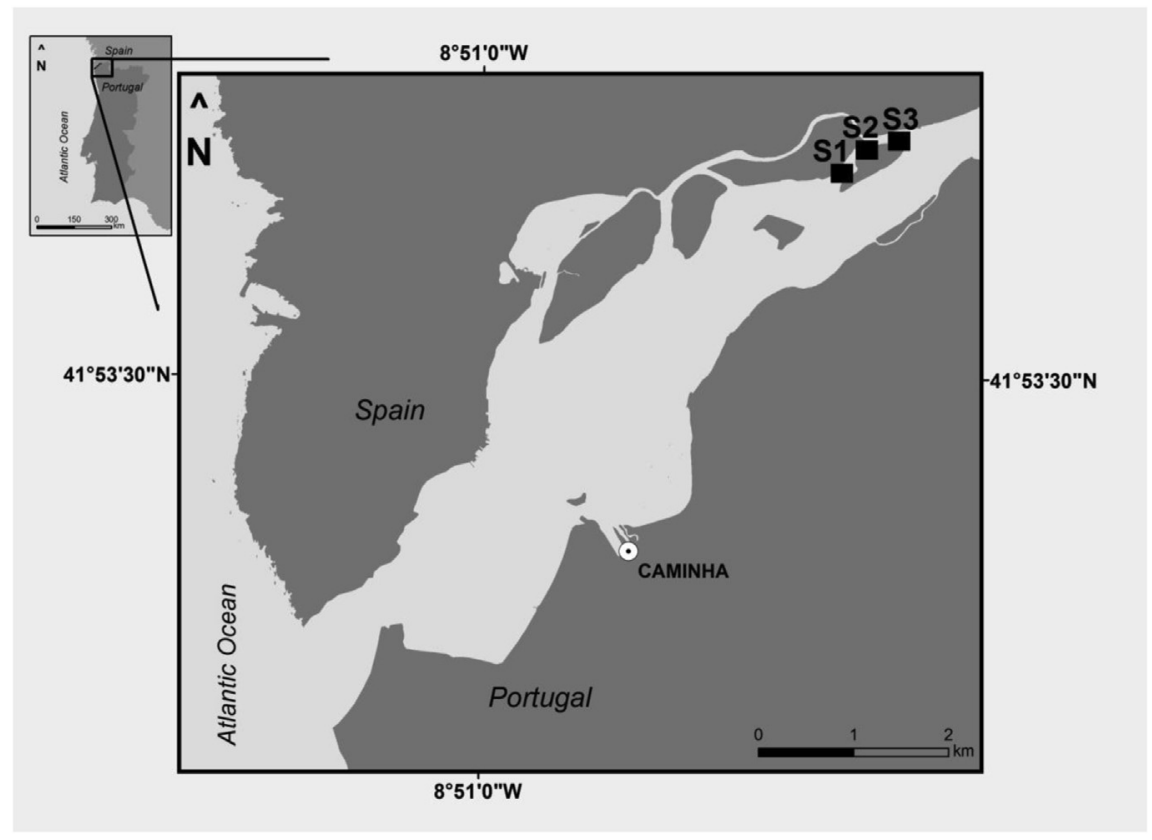

Fig. 1. Map of the study area showing the three selected sites at the lower Minho estuary, NW Iberian Peninsula. 
were normalised. A posteriori, a resemblance matrix based on the Euclidean distances was calculated, and then an ANOSIM made in a two-way crossed design, with site (that refers to Corbicula fluminea density) as a fixed factor (three levels: S1, S2 and S3) and season as a fixed factor (four levels: winter, spring, summer and autumn). In addition, with the normalized matrix, a principal component analysis (PCA) was conducted to test the possible abiotic differences among sites.

Subsequently, a permutational multivariate analysis of variance (PERMANOVA) was made to explore Corbicula fluminea density and the associated fauna patterns over space and time. This method analyses the variance of multivariate data explained by a set of explanatory factors on the basis of any distance or dissimilarity measure of choice, thereby allowing for a wide range of empirical data distributions (Anderson, 2001). C. fluminea density was statistically tested using a two-way PERMANOVA (type-III) in a twoway crossed design, with sites (three levels: S1, S2 and S3) and seasons (four levels: winter, spring, summer and autumn) as fixed factors. For the associated fauna, the data collected in tows were analyzed separately from the data collected in the fyke-nets. The overall density, and the density of each species collected in the tows and fyke-nets were statistically tested using the two-way PERMANOVA (type-III) tests with the same design described above. In addition, the ecological indexes (species richness (S), ShannonWiener index $\left(\mathrm{H}^{\prime}\right)$ and Pielou's evenness index $\left.\left(\mathrm{J}^{\prime}\right)\right)$ of the tows and fyke-nets associated fauna were calculated through the DIVERSE analysis. Subsequently, two-way PERMANOVA (type-III) tests using the same design previously described were used to the ecological indices. In all PERMANOVA tests, the statistical significance of variance was tested using 9999 permutations of residuals under a reduced model. When the number of permutations was lower than 150, the Monte Carlo $p$-value was considered. Pairwise comparisons between the two levels of each significant factor were also performed for all PERMANOVA tests.

A canonical analysis of principal coordinates (CAP) was also performed with the fauna collected associated to the tows and fyke-nets. CAP is a constrained ordination procedure that initially calculates unconstrained principal coordinate axes, followed by canonical discriminant analysis on the principal coordinates to maximize separation between predefined groups (Anderson and Robinson, 2003). For this analysis data were normalised and the Euclidian distance used (factors: site and season).

In addition, a Distance-based Linear Model (DistLM) procedure was used to analyze the relationship between the increasing density of Corbicula fluminea and the associated fauna (tows and fykenets). For the model used for the DistLM, the AIC (Akaike Information Criterion) was selected, basing the analysis on the Euclidean distance resemblance measure of the associated fauna (abundance data).

PRIMER analytical software (vers. 6.1.6, PRIMER-E Ltd, Plymouth, U.K.) with PERMANOVA+1.0.1 add-on (Anderson et al., 2008) was used for all multivariate routines.

\section{Results}

\subsection{Abiotic characterization}

The two-way ANOSIM showed that there were no statistical differences in abiotic data (temperature, salinity, pH, DO and ORP) between sampling sites ( $R$ ho $=0.25 ; p>0.05$ ); however, significant differences were detected among seasons $($ Rho $=0.91 ; p<0.05)$ (Table 1).

The PCA analysis revealed a marked difference among seasons. Its first two axes explained $89.0 \%$ of the variance (PC1 $=70.6 \%$ and PC2 $=18.4 \%$, with all the abiotic parameters of each season
Table 1

Mean $( \pm \mathrm{SD})$ values of the abiotic data: temperature $\left({ }^{\circ} \mathrm{C}\right)$, salinity, $\mathrm{pH}$, dissolved oxygen $\left(\mathrm{mg} \mathrm{L}^{-1}\right)$ and redox potential $(\mathrm{mV})$.

\begin{tabular}{|c|c|c|c|c|}
\hline \multicolumn{5}{|l|}{ Seasons } \\
\hline $\begin{array}{l}\text { Abiotic } \\
\text { variables }\end{array}$ & Winter & Spring & Summer & Autumn \\
\hline $\begin{array}{l}\text { Temperature } \\
\quad\left({ }^{\circ} \mathrm{C}\right)\end{array}$ & $9.39 \pm 0.1$ & $12.56 \pm 0.05$ & $20.81 \pm 0.31$ & $14.62 \pm 0.03$ \\
\hline Salinity & $0.06 \pm 0.01$ & $0.10 \pm 0.02$ & $10.92 \pm 1.18$ & $0.12 \pm 0.02$ \\
\hline $\mathrm{pH}$ & $7.64 \pm 0.09$ & $7.73 \pm 0.06$ & $7.91 \pm 0.16$ & $7.81 \pm 0.06$ \\
\hline $\begin{array}{l}\text { Dissolved } \\
\text { oxygen } \\
\left(\mathrm{mg} \mathrm{L}^{-1}\right)\end{array}$ & $10.55 \pm 0.13$ & $8.30 \pm 0.13$ & $8.67 \pm 0.23$ & $8.65 \pm 0.11$ \\
\hline $\begin{array}{l}\text { Redox } \\
\text { potential } \\
(\mathrm{mV})\end{array}$ & $279.27 \pm 21.64$ & $301.93 \pm 11.56$ & $219.53 \pm 7.81$ & $128.40 \pm 2.50$ \\
\hline
\end{tabular}

differing from each other (Fig. 2). Summer presented the highest values of salinity, temperature and $\mathrm{pH}$. The difference between seasons was mainly related to the higher values of dissolved oxygen during spring. Winter and autumn also presented higher values of redox potential but differed mainly due to lower values of salinity measured during the winter (Fig. 2).

\subsection{Biotic characterization}

\subsubsection{C. fluminea density}

The density of Corbicula fluminea varied significantly throughout the sampling sites (sites: Pseudo-F $=359.58, p<0.001$ ). S1 presented the lowest values of annual $C$. fluminea density (mean $\pm S E$ ) $\left(270.0 \pm 147.25\right.$ ind. $\left.\mathrm{m}^{-2}\right)$, followed by S2 (density: $1047.5 \pm 161.27$ ind. $\mathrm{m}^{-2}$ ) and S3 (density: $2986.25 \pm 210.85$ ind. $\mathrm{m}^{-2}$ ) (Fig. 3).

\subsubsection{Epibenthic assemblages - tows}

A total of 5512 individuals from nine species were collected in tows. Fishes were the most diverse group (five species) accounting for $39.7 \%$ of the total number of individuals caught, while crustaceans (four species) were the most abundant group (60.3\%). Two species accounted for $87.6 \%$ of the individuals caught, namely the brown shrimp Crangon crangon (53.9\%) and the common goby Pomatoschistus microps (33.7\%).

The density of individuals varied through space and time (Table 2). Crangon crangon, Pomatoschistus microps, Carcinus maenas and Syngnathus acus also varied significantly throughout the sampling sites and seasons (Table 2). However, the freshwater shrimp Atyaephyra desmarestii, the common prawn Palaemon serratus and the European flounder Platichthys flesus varied significantly only through time (Table 2).

The pairwise tests suggested that most of the spatial variations were associated to the high density of individuals observed in the sampling sites S2 and S3, while the seasonal variations were related to the high density of individuals recorded in summer and autumn; the exception was Atyaephyra desmarestii that presented the highest density during winter and spring (Table 2).

Similarly, the CAP analysis also showed that S2 was different from the other sampling sites and summer and autumn were different from the other seasons (Fig. 4). The CAP results also suggested that the spatial and temporal variations were important for the distinction of the epibenthic assemblage, separating them, in different groups. Significant seasonal variations were also recorded for species richness and diversity (S-Pseudo- $F=24.79, p<0.001$; $\mathrm{H}^{\prime}$-pseudo- $\left.F=13.32, p<0.001\right)($ ESM 1$)$.

The DistLM showed a significant relationship between Corbicula fluminea density and the tows associated fauna during winter and autumn (Table 3). 


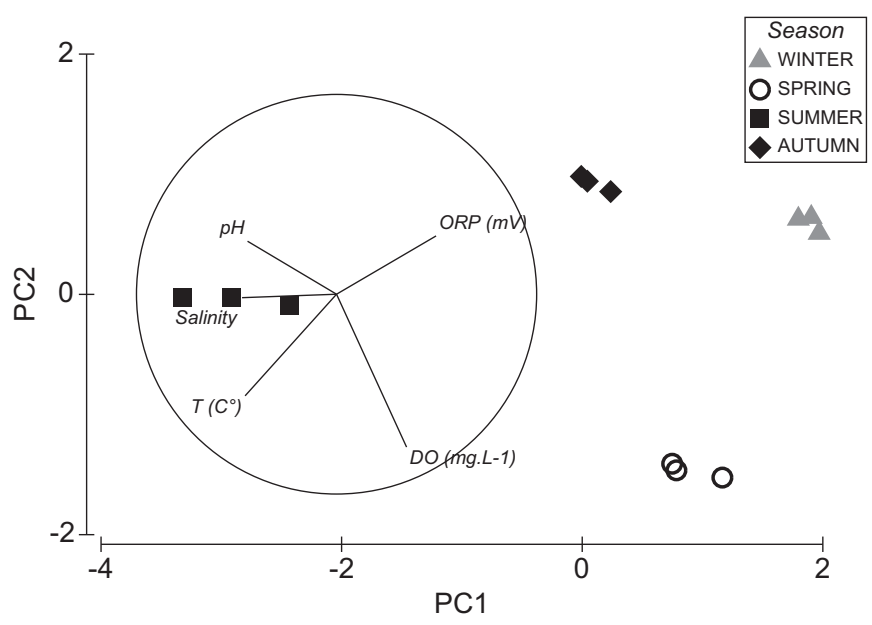

Fig. 2. PCA showing the differences of the environmental variables among sampling sites and seasons at the lower Minho estuary. $\mathbf{\Delta}=$ Winter; $\boldsymbol{\nabla}=$ Spring; $\mathbf{\square}=$ Summer; $\Delta=$ Autumn; $\mathrm{T}\left(\mathrm{C}^{\circ}\right)$ = water temperature; $\mathrm{DO}\left(\mathrm{mg} \mathrm{L}^{-1}\right)=$ dissolved oxygen; ORP $(\mathrm{mV})=$ potential redox. The first two axes explained $89.0 \%$ of the variance $(\mathrm{PC} 1=70.6 \%$ and PC2 $=18.4 \%$ )

\subsubsection{Epibenthic assemblages - fyke-nets}

A total of 1335 individuals belonging to ten species were collected in fyke-nets. Fishes were the most diverse group (seven species), representing $27.3 \%$ of the total number of individuals collected. Similarly with the tows results, crustaceans (three species) were the most abundant group, accounting for $72.7 \%$ of the total of specimens collected. The most abundant species were the common prawn Palaemon serratus (50.0\%), the shore crab Carcinus maenas (21.9\%) and the European eel Anguilla anguilla (16.4\%).

Among all collected species only the shore crab Carcinus maenas and the brown trout Salmo trutta fario varied through space and time (Table 4). Moreover, Anguilla anguilla presented significant differences among sampling sites (Table 4). There were significant differences for the abundance of individuals through seasons across most of the species: A. anguilla, Platichthys flesus, Palaemon serratus, Syngnathus acus, S. trutta fario and S. trutta trutta (Table 4).

In the pairwise results, almost no differences were observed between sampling sites, while summer was responsible for most of the differences observed among seasons (Table 4). The CAP analysis

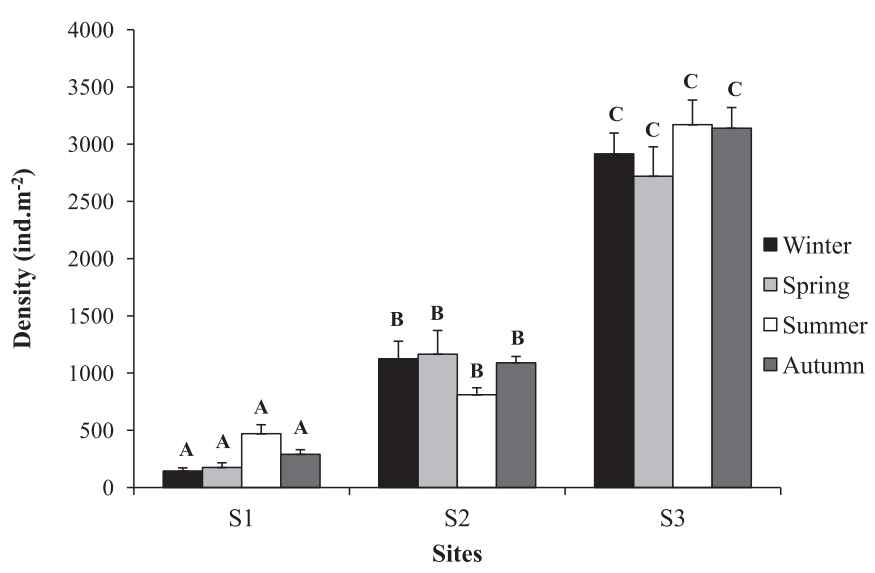

Fig. 3. C. fluminea mean $( \pm \mathrm{SE})$ density (ind. $\mathrm{m}^{-2}$ ) collected in the lower Minho estuary, NW Iberian Peninsula, per site during the four seasons. Different letters indicate significant differences among treatments (two-way PERMANOVA pairwise tests; $p<0.05$ ). Upper case letters refers to comparisons among sites (Two-way PERMANOVA, pairwise test: $p<0.05$ ). showed no distinction between sampling sites, whereas for temporal results summer was different from all the other seasons (Fig. 5).

Regarding the comparison among ecological indices, richness was the only index that presented significant differences through space and time (sites: Pseudo- $F=5.15, p<0.01$ and seasons: Pseudo- $F=25.09, p<0.001$ ). For species diversity and evenness, differences were only detected among seasons ( $\mathrm{H}^{\prime}$-Pseudo$F=15.40, p<0.001 ; \mathrm{J}^{\prime}$-Pseudo- $F=7.99, p<0.001$ ) (ESM 2). The DistLM indicated that there is no significant relationship between Corbicula fluminea density and the fyke-nets associated fauna.

\subsubsection{Epibenthic assemblages - tows versus fyke-nets}

More species (44.4\%) and individuals (93.5\%) responded to the different densities of Corbicula fluminea in the tows than in the fyke-nets (30\% and $38.9 \%$, respectively).

\subsubsection{Gut content analyses}

A total of 365 fishes had their stomach contents analyzed: Anguilla anguilla (219 individuals; size ranged from 56.9 to $762.0 \mathrm{~mm}$ ), Atherina spp. (48; size ranged from 34.6 to $107.0 \mathrm{~mm}$ ), Dicentrarchus labrax (6; size ranged from 90.0 to $237.0 \mathrm{~mm}$ ), Platichthys flesus (15; size ranged from 74.0 to $200.0 \mathrm{~mm}$ ), Syngnathus acus (64; size ranged from 35.0 to $136.0 \mathrm{~mm}$ ), Salmo trutta fario (8; size ranged from 75.0 to $295.0 \mathrm{~mm}$ ), S. trutta trutta (5; size ranged from 84.7 to $275.0 \mathrm{~mm}$ ), whereas for the crustaceans a total of 30 individuals were analyzed: Carcinus maenas (10; size ranged from 5.2 to $65.9 \mathrm{~mm}$ ), Palaemon serratus (10; size ranged from 26 to $91 \mathrm{~mm}$ ) and Procambarus clarkii (10; size ranged from 61 to $154.6 \mathrm{~mm}$ ). However, none of the specimens analyzed had parts and/or traces of Corbicula fluminea in their stomachs.

\section{Discussion}

Our results suggest that some epibenthic crustacean and fish species significantly responded to the spatial and temporal variations for both sampling techniques. More species and individuals responded to the different densities of Corbicula fluminea in the tows than in the fyke-nets suggesting that the structure provided by $C$. fluminea seems to favor the sedentary small-bodied species that are usually collected in tows. The DistLM results strengthen this finding. These species probably use the available substrata provided by $C$. fluminea shells as refuges to avoid predators and competitors and physical and/or physiological stress (Gutiérrez et al., 2003). The high filtration rates and the high capacity of sediment reworking of $C$. fluminea can contribute to important abiotic changes in water clarity, oxygen, redox potential, amount of organic matter, particle size and sediment chemistry (Phelps, 1994; Hakenkamp and Palmer, 1999; Hakenkamp et al., 2001; Vaughn and Hakenkamp, 2001; Sousa et al., 2009), which can also directly or indirectly influence the density of sedentary smallbodied epibenthic species.

The species Crangon crangon, Carcinus maenas, Pomatoschistus microps and Syngnathus acus captured in the tows were influenced by Corbicula fluminea increasing densities all over the seasons. However, only $C$. crangon, $P$. microps and $S$. acus increased their densities with increased $C$. fluminea density. For these species, the structure provided by $C$. fluminea shells is likely to be one of the main factors responsible for the differences observed, when the abiotic factors did not vary throughout the sites. It is also of note that the deposition of ingested particles as faeces and pseudofaeces by $C$. fluminea can be used as an important food resource and this cannot be omitted as an important contributing factor for the results obtained (Ricciardi et al., 1997). 
Table 2

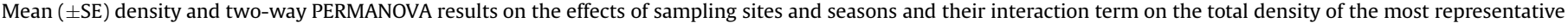
species collected with the tows in the lower Minho estuary, NW Iberian Peninsula.

\begin{tabular}{|c|c|c|c|c|c|c|c|}
\hline \multirow[t]{2}{*}{ Species|site } & \multicolumn{4}{|l|}{ Seasons } & \multicolumn{3}{|c|}{ Two-way PERMANOVA } \\
\hline & Winter & Spring & Summer & Autumn & Sites & Seasons & Interaction \\
\hline \multicolumn{8}{|l|}{ Density } \\
\hline S1 & $2.8 \pm 1.1^{(\mathrm{A})}$ & $30.8 \pm 6.2^{\mathrm{a}(\mathrm{B})}$ & $34.8 \pm 6.6^{\mathrm{a}(\mathrm{BC})}$ & $163.0 \pm 52.3^{\mathrm{a}(\mathrm{CD})}$ & Pseudo- $F=10.21^{* *}$ & Pseudo- $F=76.62^{* *}$ & Pseudo- $F=5.95^{* *}$ \\
\hline S2 & $7.3 \pm 3.5^{(\mathrm{A})}$ & $39.0 \pm 17.9^{\mathrm{ab}(\mathrm{A})}$ & $112.5 \pm 19.0^{\mathrm{b}(\mathrm{B})}$ & $448.3 \pm 84.6^{\mathrm{b}(\mathrm{C})}$ & & & \\
\hline S3 & $8.8 \pm 3.5^{(\mathrm{A})}$ & $8.5 \pm 0.9^{\mathrm{b}(\mathrm{A})}$ & $89.5 \pm 25.2^{\mathrm{ab}(\mathrm{B})}$ & $433.0 \pm 22.1^{\mathrm{b}(\mathrm{C})}$ & & & \\
\hline \multicolumn{8}{|l|}{ C. crangon } \\
\hline S1 & $0.0 \pm 0.0^{(\mathrm{A})}$ & $1.0 \pm 0.4^{(\mathrm{A})}$ & $2.0 \pm 1.2^{(\mathrm{A})}$ & $117.5 \pm 39.8^{\mathrm{a}(\mathrm{B})}$ & Pseudo- $F=8.92^{* *}$ & Pseudo- $F=120.10^{* *}$ & Pseudo- $F=8.11^{* *}$ \\
\hline S2 & $0.3 \pm 0.3^{(\mathrm{A})}$ & $0.0 \pm 0.0^{(\mathrm{A})}$ & $3.3 \pm 0.3^{(\mathrm{B})}$ & $282.8 \pm 49.7^{\mathrm{b}(\mathrm{C})}$ & & & \\
\hline S3 & $1.0 \pm 1.0^{(\mathrm{A})}$ & $1.5 \pm 0.9^{(\mathrm{A})}$ & $10.8 \pm 6.4^{(\mathrm{A})}$ & $322.3 \pm 13.3^{\mathrm{b}(\mathrm{B})}$ & & & \\
\hline \multicolumn{8}{|l|}{ P. microps } \\
\hline S1 & $1.0 \pm 0.4^{(\mathrm{A})}$ & $16.8 \pm 3.4^{\mathrm{a}(\mathrm{B})}$ & $8.5 \pm 1.9^{\mathrm{a}(\mathrm{BC})}$ & $28.0 \pm 9.4^{\mathrm{a}(\mathrm{BD})}$ & Pseudo- $F=16.49^{* *}$ & Pseudo- $F=29.96^{* *}$ & Pseudo- $F=5.83^{* *}$ \\
\hline S2 & $1.3 \pm 0.6^{(\mathrm{A})}$ & $24.5 \pm 9.4^{\mathrm{ab}(\mathrm{A})}$ & $83.0 \pm 14.0^{\mathrm{b}(\mathrm{B})}$ & $158.0 \pm 37.7^{\mathrm{b}(\mathrm{BC})}$ & & & \\
\hline S3 & $7.3 \pm 3.6^{(\mathrm{A})}$ & $3.3 \pm 1.4^{\mathrm{b}(\mathrm{A})}$ & $29.0 \pm 13.0^{\mathrm{a}(\mathrm{A})}$ & $103.5 \pm 9.1^{\mathrm{bc}(\mathrm{B})}$ & & & \\
\hline \multicolumn{8}{|l|}{ S. acus } \\
\hline S1 & $0.0 \pm 0.0^{(\mathrm{A})}$ & $0.0 \pm 0.0^{(\mathrm{A})}$ & $11.0 \pm 1.7^{\mathrm{a}(\mathrm{B})}$ & $5.0 \pm 1.5^{(\mathrm{C})}$ & Pseudo- $F=8.67^{* *}$ & Pseudo- $F=57.79^{* *}$ & Pseudo- $F=10.23^{* *}$ \\
\hline S2 & $0.0 \pm 0.0^{(\mathrm{A})}$ & $0.0 \pm 0.0^{(\mathrm{A})}$ & $11.3 \pm 3.6^{\mathrm{a}(\mathrm{B})}$ & $3.0 \pm 1.1^{(\mathrm{BC})}$ & & & \\
\hline S3 & $0.0 \pm 0.0^{(\mathrm{A})}$ & $0.3 \pm 0.3^{(\mathrm{A})}$ & $32.5 \pm 5.1^{\mathrm{b}(\mathrm{B})}$ & $2.5 \pm 1.3^{(\mathrm{A})}$ & & & \\
\hline \multicolumn{8}{|l|}{ C. maenas } \\
\hline S1 & $0.0 \pm 0.0^{(\mathrm{A})}$ & $0.0 \pm 0.0^{(\mathrm{A})}$ & $0.5 \pm 1.0^{(\mathrm{A})}$ & $9.0 \pm 11.8^{\mathrm{a}(\mathrm{B})}$ & Pseudo- $F=1.48^{\mathrm{ns}}$ & Pseudo- $F=8.10^{* *}$ & Pseudo- $F=3.56^{*}$ \\
\hline S2 & $0.0 \pm 0.0^{(\mathrm{A})}$ & $0.0 \pm 0.0^{(\mathrm{A})}$ & $0.5 \pm 2.5^{(\mathrm{AB})}$ & $2.0 \pm 3.0^{\mathrm{b}(\mathrm{B})}$ & & & \\
\hline S3 & $0.0 \pm 0.0$ & $0.0 \pm 0.0$ & $2.0 \pm 9.0$ & $0.0 \pm 5.3^{\mathrm{ab}}$ & & & \\
\hline \multicolumn{8}{|l|}{ A. desmarestii } \\
\hline S1 & $1.0 \pm 1.0$ & $7.3 \pm 3.4$ & $0.5 \pm 0.5$ & $0.0 \pm 0.0$ & Pseudo- $F=1.56^{\mathrm{ns}}$ & Pseudo- $F=2.84^{*}$ & Pseudo- $F=0.54^{\mathrm{ns}}$ \\
\hline S2 & $5.3 \pm 3.1$ & $10.8 \pm 9.4$ & $0.3 \pm 0.3$ & $0.5 \pm 0.5$ & & & \\
\hline S3 & $0.0 \pm 0.0^{(\mathrm{A})}$ & $1.5 \pm 0.7^{\mathrm{b}(\mathrm{B})}$ & $0.0 \pm 0.0^{(\mathrm{AC})}$ & $0.0 \pm 0.0^{(\mathrm{ABC})}$ & & & \\
\hline \multicolumn{8}{|l|}{ P. serratus } \\
\hline S1 & $0.0 \pm 0.0^{(\mathrm{A})}$ & $0.3 \pm 0.3^{(\mathrm{A})}$ & $12.3 \pm 4.5^{(\mathrm{B})}$ & $3.5 \pm 1.9^{(\mathrm{AB})}$ & Pseudo- $F=6.22^{\mathrm{ns}}$ & Pseudo- $F=20.93^{*}$ & Pseudo- $F=0.13^{\mathrm{ns}}$ \\
\hline S2 & $0.0 \pm 0.0$ & $0.0 \pm 0.0$ & $13.3 \pm 5.7$ & $0.8 \pm 0.8$ & & & \\
\hline S3 & $0.0 \pm 0.0^{(\mathrm{A})}$ & $0.0 \pm 0.0^{(\mathrm{A})}$ & $12.8 \pm 2.6^{(\mathrm{B})}$ & $1.3 \pm 1.0^{(\mathrm{A})}$ & & & \\
\hline \multicolumn{8}{|l|}{ P. flesus } \\
\hline $\mathrm{S} 1$ & $0.8 \pm 0.3^{(\mathrm{A})}$ & $4.8 \pm 1.4^{(\mathrm{B})}$ & $0.0 \pm 0.0^{(\mathrm{C})}$ & $0.5 \pm 0.3^{(\mathrm{AC})}$ & Pseudo- $F=0.96^{\text {ns }}$ & Pseudo- $F=11.33^{* *}$ & Pseudo- $F=1.33^{\mathrm{ns}}$ \\
\hline S2 & $0.5 \pm 0.5^{(\mathrm{AB})}$ & $3.0 \pm 1.1^{(\mathrm{A})}$ & $0.0 \pm 0.00^{\mathrm{AB})}$ & $1.3 \pm 0.5^{(\mathrm{A})}$ & & & \\
\hline S3 & $0.5 \pm 0.3$ & $1.8 \pm 1.4$ & $0.3 \pm 0.3$ & $0.8 \pm 0.3$ & & & \\
\hline
\end{tabular}

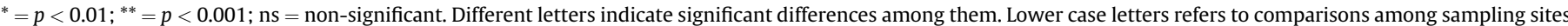
(column), while upper case letters in brackets refers to comparisons among seasons (row) (Two-way PERMANOVA, pairwise test: $p<0.05$ ).

Furthermore, Corbicula fluminea associated fauna (described in detail in Ilarri et al., 2012) is probably an important food resource for Crangon crangon (Oh et al., 2001; Ilarri et al., 2012), Pomatoschistus microps (Leitão et al., 2006) and Syngnathus acus (Kedrick and Hyndes, 2005; Oliveira et al., 2007). Since sites with high densities of $C$. fluminea have a higher density of macrozoobenthic potential prey it is possible that the above mentioned epibenthic species respond positively to this situation. In addition, Pomatoschistus spp. species may use bivalve shells to establish territory and guard eggs (Nyman, 1953) and probable P. microps also use $C$. fluminea shells for this purpose. The same is true for Syngnathids since highly complex habitats provided by bivalves allow them to be better camouflaged (Ryer, 1988; Berglund, 1993) and shells are one of the components used by Syngnathidae individuals as holdfasts (Rosa et al., 2007).

In contrast, the shore crab Carcinus maenas presented higher densities in S1, thus was negatively influenced by the density of Corbicula fluminea. However, in the case of $C$. maenas its preference for areas with low $C$. fluminea densities can be related to the ecological interactions among associated fauna, since $C$. maenas also prey on species associated to $C$. fluminea such as the brown shrimp and the common goby that are among the preferred prey
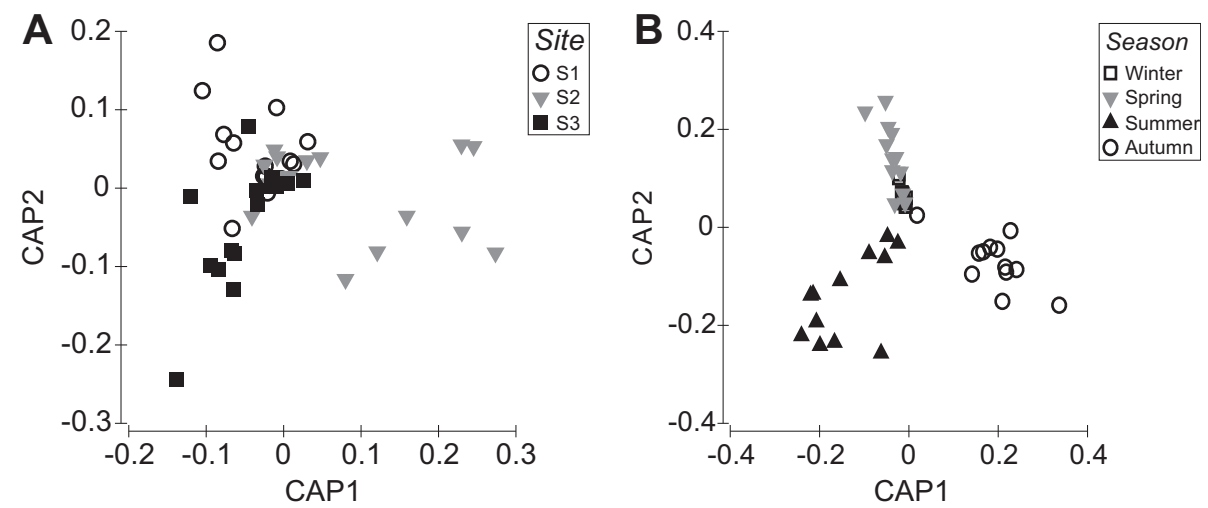

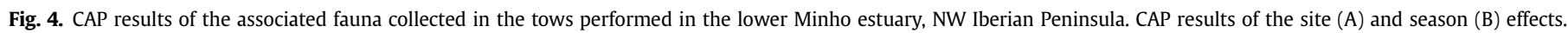


Table 3

Results of the DistLM analysis performed with the epibenthic fauna data collected in the tows during the seasons in which significant relationship between $C$. fluminea density and the epibenthic associated fauna were observed.

\begin{tabular}{lllllll}
\hline Winter & & & & & & \\
Marginal tests & - & SS(trace) & Pseudo-F & P & Prop. & - \\
C. fluminea density & - & 98.13 & 2.65 & 0.047 & 0.21 & - \\
Sequential tests & AIC & SS(trace) & Pseudo-F & P & Prop. & Cumul \\
+ C. fluminea density & 45.152 & 98.14 & 2.65 & 0.047 & 0.21 & 0.21 \\
Autumn & & & & & & \\
Marginal tests & - & SS(trace) & Pseudo-F & P & Prop. & - \\
C. fluminea density & - & 72.09 & 5.70 & 0.024 & 0.36 & - \\
Sequential tests & AIC & SS(trace) & Pseudo-F & P & Prop. & Cumul \\
+ C. fluminea density & 115.16 & 72.09 & 5.70 & 0.024 & 0.36 & 0.36 \\
\hline
\end{tabular}

items of $C$. maenas inside estuaries (Baeta et al., 2006). In addition, is possible that the high shelter availability provided by $C$. fluminea shells in S2 and S3 may impair the predatory capacity of the shore crab and so $C$. maenas may prefer S1, given that in this site it can feed more efficiently on its prey. However, further studies are necessary to better understand the ecological interactions between C. maenas and the associated fauna.

In the fyke-nets the species Carcinus maenas, Anguilla anguilla and Salmo trutta fario were influenced by Corbicula fluminea increasing densities during the different seasons. C. maenas presented the same pattern observed for the tows. However, A. anguilla in most of the seasons increased its density with $C$. fluminea increased density; this was also observed for $S$. trutta fario, except that this species was only observed in the winter. These two species present a diversified diet, represented mainly by benthic macrozoobenthic and fish species; they probably use $C$. fluminea structure for foraging activity, since no trace of $C$. fluminea were found in their gut contents. Sites with high densities of $C$. fluminea are colonized by several macrozoobenthic and fish species that were already described to be part of the European eel and brown trout diets (De Nie, 1987; Froese and Pauly, 2012). Despite A. anguilla being an opportunistic feeder (Schulze et al., 2004), some studies have also demonstrated that this species has a preference for chironomid larvae (Doemer et al., 2006), which was one of the main items associated to $C$. fluminea in the study area (Ilarri et al., 2012).

In addition to the spatial differences observed for the epibenthic species, strong seasonal variations were also detected. This is probably due to the high variation of the abiotic factors through seasons, especially salinity, temperature and river discharge. Indeed, the selected sites are located in a transient area in which, depending on the season, there is a great input of salt water (mainly in the summer), due to the tide influence (e.g. in summer during high tides salinity can reach 20 in the study area), or freshwater, as a result of the river discharge (e.g. in winter salinity is almost always around 0.05 ).

Furthermore, the fish and crustaceans species of the Minho estuary do not seem to prey on Corbicula fluminea and this could also be one of the reasons behind the high densities of $C$. fluminea in this area. It is possible that these species do not present the morphological pre-adaptations for a molluscivorous diet to act as C. fluminea predators. According to Oliveira et al. (2010), only species that can break the valves of bivalves are successful with this kind of prey. In fact, the activity of mollusc-feeding fishes is

Table 4

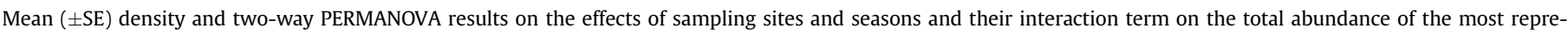
sentative species collected with the fyke-nets in the lower Minho estuary, NW Iberian Peninsula.

\begin{tabular}{|c|c|c|c|c|c|c|c|}
\hline \multirow[t]{2}{*}{ Species|site } & \multicolumn{4}{|l|}{ Seasons } & \multicolumn{3}{|c|}{ Two-way PERMANOVA } \\
\hline & Winter & Spring & Summer & Autumn & Sites & Seasons & Interaction \\
\hline \multicolumn{8}{|l|}{ Abundance } \\
\hline S1 & $1.8 \pm 1.3^{(\mathrm{A})}$ & $7.7 \pm 2.4^{(\mathrm{A})}$ & $35.0 \pm 7.0^{(\mathrm{B})}$ & $28.3 \pm 15.0^{(\mathrm{AB})}$ & \multirow[t]{3}{*}{ Pseudo- $F=0.13^{\mathrm{ns}}$} & \multirow[t]{3}{*}{ Pseudo- $F=10.92^{* *}$} & \multirow[t]{3}{*}{ Pseudo- $F=0.49^{\mathrm{ns}}$} \\
\hline S2 & $1.7 \pm 0.4^{(\mathrm{A})}$ & $13.0 \pm 3.6^{(\mathrm{B})}$ & $27.3 \pm 12.4^{(\mathrm{AB})}$ & $38.7 \pm 15.1^{(\mathrm{BC})}$ & & & \\
\hline S3 & $2.3 \pm 1.0^{(\mathrm{A})}$ & $5.8 \pm 1.0^{(\mathrm{B})}$ & $20.5 \pm 4.7^{(\mathrm{C})}$ & $40.3 \pm 11.0^{(\mathrm{CD})}$ & & & \\
\hline \multicolumn{8}{|l|}{ C. maenas } \\
\hline S1 & $0.0 \pm 0.0^{(\mathrm{A})}$ & $2.5 \pm 1.4^{(\mathrm{AC})}$ & $18.8 \pm 5.6^{\mathrm{a}(\mathrm{B})}$ & $5.7 \pm 1.8^{(\mathrm{BC})}$ & \multirow[t]{3}{*}{ Pseudo- $F=5.47^{*}$} & \multirow[t]{3}{*}{ Pseudo- $F=15.86^{* *}$} & \multirow[t]{3}{*}{ Pseudo- $F=2.98^{*}$} \\
\hline S2 & $0.0 \pm 0.0^{(\mathrm{A})}$ & $1.2 \pm 0.5^{(\mathrm{B})}$ & $8.8 \pm 2.6^{\mathrm{ab}(\mathrm{CD})}$ & $3.0 \pm 0.7^{(\mathrm{BD})}$ & & & \\
\hline S3 & $0.0 \pm 0.0^{(\mathrm{A})}$ & $0.2 \pm 0.2^{(\mathrm{A})}$ & $4.0 \pm 1.8^{\mathrm{b}(\mathrm{AB})}$ & $4.5 \pm 1.8^{(\mathrm{B})}$ & & & \\
\hline \multicolumn{8}{|l|}{ A. anguilla } \\
\hline S1 & $0.5 \pm 0.3^{(\mathrm{A})}$ & $3.2 \pm 1.0^{(\mathrm{BC})}$ & $7.0 \pm 1.9^{(\mathrm{C})}$ & $3.3 \pm 1.9^{\mathrm{ab}(\mathrm{ABC})}$ & \multirow{3}{*}{ Pseudo- $F=4.17^{*}$} & \multirow[t]{3}{*}{ Pseudo- $F=9.14^{* *}$} & \multirow[t]{3}{*}{ Pseudo- $F=2.05^{\mathrm{ns}}$} \\
\hline S2 & $0.5 \pm 0.2^{(\mathrm{A})}$ & $3.0 \pm 1.0^{(\mathrm{BC})}$ & $2.8 \pm 0.7^{(\mathrm{C})}$ & $1.0 \pm 0.4^{\mathrm{a}(\mathrm{AB})}$ & & & \\
\hline S3 & $0.5 \pm 0.2^{(\mathrm{A})}$ & $4.2 \pm 0.7^{(\mathrm{BC})}$ & $4.5 \pm 1.2^{(\mathrm{CD})}$ & $6.0 \pm 0.9^{\mathrm{ab}(\mathrm{BD})}$ & & & \\
\hline \multicolumn{8}{|l|}{ P. flesus } \\
\hline S1 & $0.0 \pm 0.0^{(\mathrm{A})}$ & $0.5 \pm 0.2^{(\mathrm{B})}$ & $0.0 \pm 0.0^{(\mathrm{A})}$ & $0.0 \pm 0.0^{(\mathrm{A})}$ & \multirow[t]{3}{*}{ Pseudo- $F=0.58^{\text {ns }}$} & \multirow[t]{3}{*}{ Pseudo- $F=3.18^{*}$} & \multirow[t]{3}{*}{ Pseudo- $F=0.58^{\mathrm{ns}}$} \\
\hline S2 & $0.3 \pm 0.2$ & $0.5 \pm 0.3$ & $0.2 \pm 0.2$ & $0.0 \pm 0.0$ & & & \\
\hline S3 & $0.5 \pm 0.3$ & $0.3 \pm 0.2$ & $0.2 \pm 0.2$ & $0.0 \pm 0.0$ & & & \\
\hline \multicolumn{8}{|l|}{ P. serratus } \\
\hline S1 & $0.0 \pm 0.0^{(\mathrm{A})}$ & $1.2 \pm 0.5^{\mathrm{ab}(\mathrm{A})}$ & $7.5 \pm 1.8^{(\mathrm{B})}$ & $18.7 \pm 12.2^{(\mathrm{AB})}$ & \multirow[t]{3}{*}{ Pseudo- $F=0.53^{\text {ns }}$} & \multirow[t]{3}{*}{ Pseudo- $F=8.78^{* *}$} & \multirow[t]{3}{*}{ Pseudo- $F=0.23^{\text {ns }}$} \\
\hline S2 & $0.0 \pm 0.0^{(\mathrm{A})}$ & $2.5 \pm 0.6^{\mathrm{a}(\mathrm{B})}$ & $12.5 \pm 9.6^{(\mathrm{AB})}$ & $33.2 \pm 15.4^{(\mathrm{AB})}$ & & & \\
\hline S3 & $0.0 \pm 0.0^{(\mathrm{A})}$ & $0.0 \pm 0.0^{\mathrm{b}(\mathrm{AD})}$ & $7.8 \pm 1.5^{(\mathrm{BC})}$ & $28.0 \pm 11.6^{(\mathrm{C})}$ & & & \\
\hline \multicolumn{8}{|l|}{ S. acus } \\
\hline S1 & $0.0 \pm 0.0$ & $0.0 \pm 0.0$ & $1.5 \pm 0.9$ & $0.7 \pm 0.3$ & \multirow[t]{3}{*}{ Pseudo- $F=1.79^{\mathrm{ns}}$} & \multirow[t]{3}{*}{ Pseudo- $F=18.20^{* *}$} & \multirow[t]{3}{*}{ Pseudo- $F=1.32^{\mathrm{ns}}$} \\
\hline S2 & $0.0 \pm 0.0^{(\mathrm{A})}$ & $0.0 \pm 0.0^{(\mathrm{A})}$ & $2.5 \pm 0.7^{(\mathrm{B})}$ & $1.2 \pm 0.3^{(\mathrm{BC})}$ & & & \\
\hline S3 & $0.0 \pm 0.0^{(\mathrm{A})}$ & $0.0 \pm 0.0^{(\mathrm{A})}$ & $3.8 \pm 1.2^{(\mathrm{B})}$ & $1.0 \pm 0.3^{(\mathrm{C})}$ & & & \\
\hline \multicolumn{8}{|l|}{ S. trutta fario } \\
\hline S1 & $0.0 \pm 0.0$ & $0.0 \pm 0.0$ & $0.0 \pm 0.0$ & $0.0 \pm 0.0$ & Pseudo- $F=2.50^{\mathrm{ns}}$ & Pseudo- $F=5.71^{* *}$ & Pseudo- $F=2.5^{*}$ \\
\hline S2 & $0.3 \pm 0.2$ & $0.0 \pm 0.0$ & $0.0 \pm 0.0$ & $0.0 \pm 0.0$ & & & \\
\hline S3 & $1.0 \pm 0.5$ & $0.0 \pm 0.0$ & $0.0 \pm 0.0$ & $0.0 \pm 0.0$ & & & \\
\hline S. trutta trutta & & & & & & & \\
\hline S1 & $0.2 \pm 0.2$ & $0.0 \pm 0.0$ & $0.0 \pm 0.0$ & $0.0 \pm 0.0$ & Pseudo- $F=0.22^{\mathrm{ns}}$ & Pseudo- $F=3.12^{*}$ & Pseudo- $F=0.50^{\mathrm{ns}}$ \\
\hline S2 & $0.2 \pm 0.2$ & $0.2 \pm 0.2$ & $0.0 \pm 0.0$ & $0.0 \pm 0.0$ & & & \\
\hline S3 & $0.3 \pm 0.2$ & $0.0 \pm 0.0$ & $0.0 \pm 0.0$ & $0.0 \pm 0.0$ & & & \\
\hline
\end{tabular}

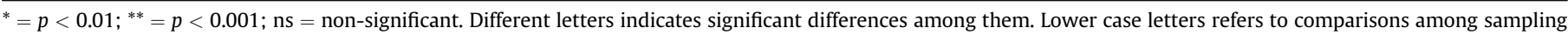
stations (column), while upper case letters in brackets refers to comparisons among seasons (row) (Two-way PERMANOVA, pairwise test: $p<0.05$ ). 

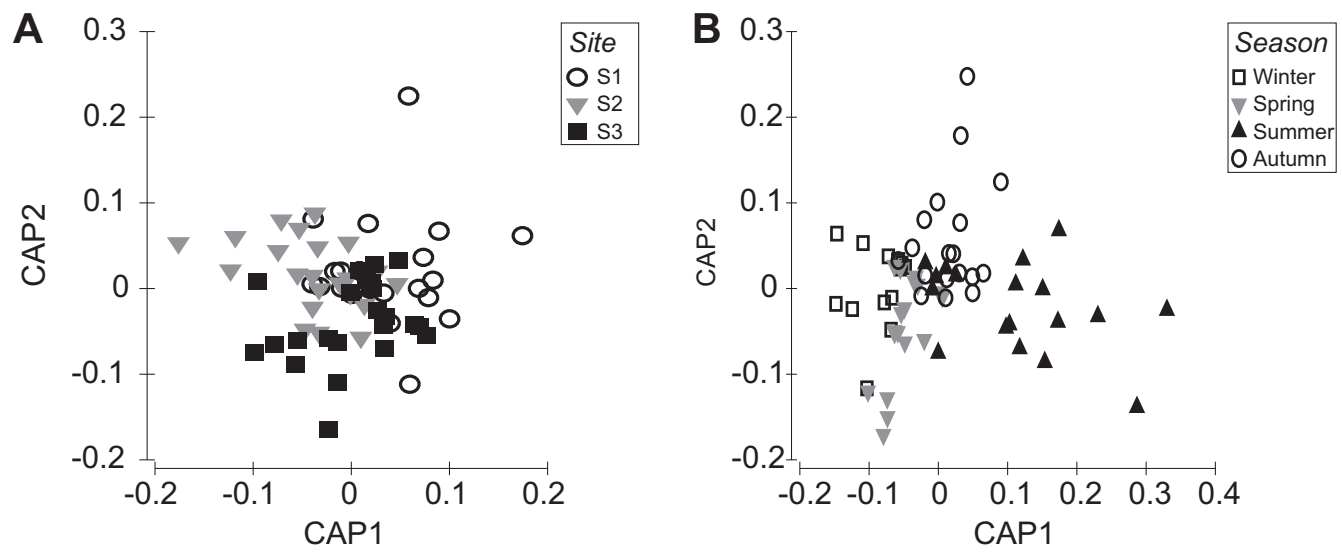

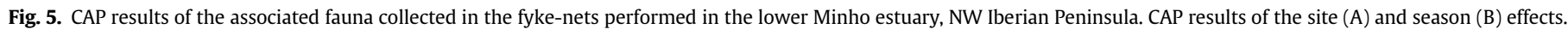

considered an effective regulator of mollusc populations (Slootweg et al., 1993). However, it is of note that $C$. fluminea juveniles were previously recorded in the gut contents of a few Platichthys flesus and Salmo trutta fario (Ilarri, personal observation), but always in very low abundance. Although $C$. fluminea seems to have no predators (or at least is subjected to a low predation pressure) in the Minho estuary, it is possible that eventually co-occurring species might adapt to prey on it; Carlsson et al. (2011) suggested that native predators need time to adapt to feed effectively on a nonnative resource. In addition, Garcia and Protogino (2005) observed that several fish species of Río de la Plata (Argentina) have modified their diet over time to feed on $C$. fluminea and on the golden mussel Limnoperna fortunei. However, the first record of $C$. fluminea in the Minho estuary was in 1989 (Araujo et al., 1993) and after more than two decades, $C$. fluminea is still barely found in the stomach contents of crustaceans and fishes on this estuarine system. On the other hand, $C$. fluminea by feeding on primary producers and by normally being eaten by predators, occupies a central position in the food web (Lercari and Bergamino, 2011), once it can connect benthic and pelagic compartments. However, in the Minho estuary, due to the absence of predators, it is possible that $C$. fluminea do not make this connection between the different compartments (the exception occur when this species is subject to very large mortalities; Ilarri et al., 2011; Sousa et al., 2012).

There are few studies that tested the influence of invasive bivalve species on the higher trophic levels and in most of the cases these were performed with Dreissenid mussels (zebra mussel Dreissena polymorpha and quagga mussel Dreissena bugensis) and Crassostrea gigas. Different results were reported, with some studies showing an increase of the density and diversity (Karataev and Burlakova, 1995; Hosack, 2003; Ruesink et al., 2005), others a decrease (Ryan et al., 1999; Pothoven and Madenjian, 2008), while others presented no influence (Richardson and Bartsch, 1997; Trometer and Busch, 1999). Several studies suggested that the influence of invasive bivalves on macroinvertebrate and pelagic assemblages is difficult to predict, since it depends of various ecological factors that are highly context dependent (Strayer et al., 2004).

\section{Conclusion}

Overall, Corbicula fluminea influenced $46.15 \%$ of the epibenthic crustacean and fish species (Crangon crangon, Anguilla anguilla, Carcinus maenas, Pomatoschistus microps, Syngnathus acus and S. truta fario) and $82.87 \%$ of the total individuals collected in this study. In most of the cases these species attained higher abundance in areas with higher $C$. fluminea densities; the only exception was
C. maenas which showed a preference for sites with a low density of $C$. fluminea. The present study suggests that $C$. fluminea shells are likely to be one of the main factors responsible for the differences observed. The physical structure provided by $C$. fluminea, when found in densities higher than 1000 individuals $/ \mathrm{m}^{2}$ can enhance conditions for the epibenthic associated fauna.

\section{Acknowledgments}

This study was part of the PhD thesis of the leading author and was financed by a grant from the Portuguese Foundation for Science and Technology-FCT (SFRH/BD/33387/2008). This work was partially supported by European Union Funds (FEDER/COMPETEOperational Competitiveness Program) and by national funds ( FCT - Portuguese Foundation for Science and Technology) under the project ECO-IAS: Ecosystem-level impacts of an invasive alien species (PTDC/AAC-AMB/116685/2010). Currently Martina Ilarri is supported by a Post-doc grant from the FCT (SFRH/BPD/90088/ 2012). Special thanks to Eduardo Martins for field assistance, Fabiana Freitas for helping with the stomach contents analyses and Rute Pinto for helping with the map.

\section{Appendix A. Supplementary data}

Supplementary data related to this article can be found at http:// dx.doi.org/10.1016/j.ecss.2014.03.017.

\section{References}

Anderson, M.J., 2001. A new method for non-parametric multivariate analysis of variance. Austral Ecol. 26, 32-46.

Anderson, M.J., Robinson, J., 2003. Generalized discriminant analysis based on distances. Aust. N. Z. J. Stat. 45, 301-318.

Anderson, M.J., Gorley, R.N., Clarke, K.R., 2008. PERMANOVA+ for PRIMER: Guide to Software and Statistical Methods. PRIMER-E, Plymouth.

Araujo, R., Moreno, D., Ramos, M.A., 1993. The asiatic clam Corbicula fluminea (Müller, 1774) (Bivalvia: Corbiculidae) in Europe. Am. Malacol. Bull. 10, 39-49.

Baeta, A., Cabral, H.N., Marques, J.C., Pardal, M.A., 2006. Feeding ecology of the green crab, Carcinus maenas (L., 1758) in a temperate estuary, Portugal. Crustaceana 79, 1181-1193.

Berglund, A., 1993. Risky sex: male pipefish mate at random in the presence of a predator. Anim. Behav. 46, 169-175.

Byrnes, J.E., Reynolds, P.L., Stachowicz, J.J., 2007. Invasions and extinctions reshape coastal marine food weebs. PLos One 2, 295.

Carlsson, N.O.L., Bustamante, H., Strayer, D.L., Pace, M.L., 2011. Biotic resistance on the increase: native predators structure invasive zebra mussel populations. Freshw. Biol. 56, 1630-1637.

Crooks, J.A., 2002. Characterizing ecosystem-level consequences of biological invasions: the role of ecosystem engineers. Oikos 97, 153-166.

De Nie, H.W., 1987. Food, feeding periodicity and consumption of the eel Anguilla anguilla (L.) in the shallow eutrophic Tjeukemeer (The Netherlands). Arch. Hydrobiol. 95, 307-310. 
Doemer, H., Skov, C., Berg, S., Schulze, T., Beare, D., Van der Velde, G., 2006. The Diet of Large Eels (Anguilla anguilla) in relation to Food Availability. ICES Annual Science Conference Proceedings, pp. 1-30.

Ferreira, J.G., Simas, T., Nobre, A., Silva, M.C., Shifferegger, K., Lencart-Silva, J., 2003. Identification of Sensitive Areas and Vunerable Zones in Transitional and Coastal Portuguese Systems. Application of the United States National Estuarine Eutrophication Assessment to the Minho, Lima, Douro, Ria de Aveiro, Mondego, Tagus, Sado, Mira, Ria Formosa and Guadiana systems. Instituto da Água e Instituto do Mar, Ideias Virtuais, Lisboa.

Freitas, V., Costa-Dias, S., Campos, J., Bio, A., Santos, P., Antunes, C., 2009. Patterns in abundance and distribution of juvenile flounder Platichthys flesus, in Minho estuary (NW Iberian Peninsula). Aquat. Ecol. 43, 1143-1153.

Froese, R., Pauly, D., 2012. Fishbase-World Wide Web Electronic Publication. WWW Page. www.fishbase.org (accessed 04.02.12.).

Garcia, M.L., Protogino, L.C., 2005. Invasive freshwater molluscs are consumed by native fishes in South America. J. Appl. Ichthyol. 21, 34-38.

Grosholz, E., 2002. Ecological and evolutionary consequences of coastal invasions. Trends Ecol. Evol. 17, 22-27.

Gutiérrez, J.L., Jones, C.G., Strayer, D.L., 2003. Mollusks as ecosystem engineers: the role of shell production in aquatic habitats. Oikos 101, 79-90.

Hakenkamp, C.C., Palmer, M.A., 1999. Introduced bivalves in freshwater ecosystems: the impact of Corbicula on organic matter dynamics in a sandy stream. Oecologia 119, 445-451.

Hakenkamp, C.C., Ribblett, S.G., Palmer, M.A., Swan, C.M., Reid, J.W., Goodison, M.R., 2001. The impact of an introduced bivalve (Corbicula fluminea) on the benthos of a sandy stream. Freshw. Biol. 46, 491-501.

Hosack, G., 2003. Effects of Zostera marina and Crassostrea gigas Culture on the Intertidal Communities of Willapa Bay, Washington. Ms Thesis. Univ. Wash, Seattle.

Ilarri, M., Antunes, C., Guilhermino, L., Sousa, R., 2011. Massive mortality of the Asian clam Corbicula fluminea in a highly invaded area. Biol. Invas. 13, 277-280.

Ilarri, M.I., Sousa, R., 2012. Corbicula fluminea Müller (Asian clam). In: Francis, A (Ed.), A Handbook of Global Freshwater Invasive Species. Earthscan, London, UK, pp. 173-183.

Ilarri, M.I., Freitas, F., Costa-Dias, S., Antunes, C., Guilhermino, L., Sousa, R., 2012. Associated macrozoobenthos with the invasive Asian clam Corbicula fluminea J. Sea Res. 72, 113-120.

Karataev, A.Y., Burlakova, L.E., 1995. The role of Dreissena in lake ecosystems. Russ. J. Ecol. 26, 207-211.

Kedrick, A.J., Hyndes, G.A., 2005. Variations in the dietary compositions of morphologically diverse syngnathid fishes, Environ. Biol. Fishes 72, 415-427.

Lercari, D., Bergamino, L., 2011. Impacts of two invasive Mollusks, Rapana venosa (Gastropoda) and Corbicula fluminea (Bivalvia), on the food web structure of Río de la Plata estuary and nearshore oceanic ecosystem. Biol. Invas. 13, 2053-2061.

Leitão, R., Martinho, F., Neto, J.M., Cabral, H., Marques, J.C., Pardal, M.A., 2006. Feeding ecology, population structure and distribution of Pomatoschistus microps (Krøyer, 1838) and Pomatoschistus minutes (Pallas, 1770) in a temperate estuary, Portugal. Estuar. Coast. Shelf Sci. 66, 231-239.

Mayer, C.M., VanDeValk, A.J., Forney, J.L., Rudstam, L.G., Mills, E.L., 2000. Response of yellow perch (Perca flavescens) in Oneida Lake, New York, to the establishment of zebra mussels (Dresseina polymorpha). Can. J. Fish. Aqua. Sci. 57, 742-754.

Mouthon, J., 1981. Sur la présence en France et au Portugal de Corbicula (Bivalvia, Corbiculidae) originaire d'Asie. Basteria 45, 109-116.

Nyman, K.J., 1953. Observations on the behavior of Gobius microps. Acta Soc. Pro Fauna Flora Fenn. 69, 1-11.

Oh, C.-W., Hartnoll, R.G., Nash, R.D.M., 2001. Feeding ecology of the common shrimp Crangon crangon in Port Erin Bay, Isle of Man, Irish sea. Mar. Ecol. Prog. Ser. 214 $211-223$

Oliveira, F., Erzini, K., Gonçalves, J.M.S., 2007. Feeding habits of the deep-snouted pipefish Syngnathus typhle in a temperate coastal lagoon. Estuar. Coast Shelf Sci. 72, 337-347.

Oliveira, C.R.C., Fugi, R., Brancalhão, K.P., Agostinho, A.A., 2010. Fish as potential controllers of invasive Mollusks in a Neotropical Reservoir. Nat. Conserv. 8, 140 144.

Phelps, H.L. 1994. The Asiatic clam (Corbicula fluminea) invasion and system-level ecological change in the Potomac River Estuary near Washington, D.C. Estuaries $17,614-621$.

Pothoven, S.A., Madenjian, C.P., 2008. Changes in consumption by alewives and lake white fish after dreissenid mussel invasions in Lake Michigan and Huron. North Am. J. Fish. Manag. 28, 308-320.

Ricciardi, J.D., Debuse, V.J., Aldridge, D.C., 1997. Host specialization in an unusua symbiosis: European bitterlings spawning in freshwater mussels. Oikos 78 539-545.

Ricciardi, A., Atkinson, S.K., 2004. Distinctiveness magnifies the impact of biological invaders in aquatic ecosystems. Ecol. Lett. 7, 781-784.

Richter, B.D., Braun, D.P., Mendelson, M.A., Master, L.L., 1997. Threats to imperiled freshwater fauna. Conserv. Biol. 11, 1081-1093.

Richardson, W.B., Bartsch, L.A., 1997. Effects of zebra mussels on food webs: interactions with juvenile bluegills and water residence time. Hydrobiologia 354 $141-150$.
Rosa, I.L., Oliveira, T.P.R., Castro, A.L.C., Moraes, L.E.S., Xavier, J.H.A., Nottingham, M.C., Dias, T.L.P., Bruto-Costa, L.V., Araújo, M.E., Birolo, A.B., Mai, A.C.G., Monteiro-Neto, C., 2007. Population characteristics, space use and habitat associations of the seahorse Hippocampus reidi (Teleostei: Syngnathidae). Neotrop. Ichthyol. 5, 405-414.

Ruesink, J.L., Lenihan, H.S., Trimble, A.C., Heiman, K.W., Micheli, F., Byers, J.E., Kay, M.C., 2005. Introduction of non-native oysters: ecosystem effects and restoration implications. Annu. Rev. Ecol. Evol. Syst. 36, 643-689.

Ryan, P.A., Witzel, L.D., Paine, J., Freeman, M., Hardy, M., Scholten, S., Sztramko, L., MacGregor, R., 1999. Recent trends in fish populations in eastern Lake Erie in relation to changing lake trophic state and food web. In: Munawar, M., Edsall, T., Munawar, I.F. (Eds.), State of Lake Erie (SOLE): Past, Present and Future, Ecovision World Monograph Series. The Netherlands Backhuys Publishers, Leiden, pp. 241-289.

Ryer, C.H., 1988. Pipefish foraging: effects of fish size, prey size and altered habitat complexity. Mar. Ecol. Prog. Ser. 48, 37-45.

Schulze, T., Kahl, U., Radke, R.J., Beendorf, J., 2004. Consumption, abundance, and habitat use of Anguilla anguilla in a mesotrophic reservoir. J. Fish. Biol. 65, 15431562.

Simberloff, D., Martin, J.-L., Genovesi, P., Maris, V., Wardle, D.A., Aronson, J., Courchamp, F., Galil, B., Garcia-Berthou, E., Pascal, M., Pyšek, P., Sousa, R., Tabacchi, E., Vilà, M., 2013. Impacts of biological invasions: what's what and the way forward. Trends Ecol. Evol. 28, 58-66.

Slootweg, R., Vroeg, P.A., Wiersma, S.J., 1993. Effects of molluscivorous fish, water quality and pond management on the development of schistosomiasis vector in aquaculture ponds. Aquac. Fish Manag. 24, 123-128.

Sousa, R., Guilhermino, L., Antunes, C., 2005. Molluscan fauna in the freshwater tidal area of the River Minho estuary, NW of Iberian Peninsula. Ann. De. Limnol. Int. J. Limnol. 41, 141-147.

Sousa, R., Freire, R., Rufino, M., 2007a. Genetic and shell morphological variability of the invasive bivalve Corbicula fluminea (Müller, 1774) in two Portuguese estuaries. Estuar. Coast Shelf Sci. 74, 166-174.

Sousa, R., Antunes, C., Guilhermino, L., 2007b. Species composition and monthly variation of the Molluscan fauna in the freshwater subtidal area of the River Minho estuary. Estuar. Coast Shelf Sci. 75, 90-100.

Sousa, R., Rufino, M., Gaspar, M., Antunes, C., Guilhermino, L., 2008a. Abiotic impacts on spatial and temporal distribution of Corbicula fluminea (Müller, 1774) in the River Minho estuary, Portugal. Aquat. Conserv. 18, 98-110.

Sousa, R., Nogueira, A.J.A., Gaspar, M., Antunes, C., Guilhermino, L., 2008b. Growth and extremely high production of the non-indigenous invasive species Corbicula fluminea (Müller, 1774): possible implications for ecosystem functioning. Estuar. Coast Shelf Sci. 80, 289-295.

Sousa, R., Dias, S., Freitas, V., Antunes, C., 2008c. Subtidal macrozoobenthic assemblages along the River Minho estuarine gradient (north-west Iberian Peninsula). Aquat. Conserv. 18, 1063-1077.

Sousa, R., Antunes, C., Guilhermino, L., 2008d. Ecology of the invasive Asian clam Corbicula fluminea (Müller, 1774) in aquatic ecosystems: an overview. Ann. De. Limnol. - Int. J. Limnol. 44, 85-94.

Sousa, R., Gutiérrez, J.L., Aldridge, D., 2009. Non indiginous bivalves as ecosystem engineers. Biol. Invas. 11, 2367-2385.

Sousa, R., Morais, P., Dias, E., Antunes, C., 2011. Biological invasions and ecosystem functioning: time to merge. Biol. Invas. 13, 1055-1058.

Sousa, R., Novais, A., Costa, R., Strayer, D., 2013. Invasive bivalves in fresh waters: impacts from individuals to ecosystems and possible control strategies. Hydrobiologia (in press).

Sousa, R., Varandas, S., Cortes, R., Teixeira, A., Lopes-Lima, M., Machado, J., Guilhermino, L., 2012. Massive die-offs of freshwater bivalves as resource pulses. Int. J. Limnol. 48, 105-112.

Strayer, D.L., Hattala, K.A., Kahnle, A.W., 2004. Effects of an invasive bivalve (Dreissena polymorpha) on fish in the Hudson River estuary. Can. J. Fish. Aqua. Sci. 61, 924-941.

Strayer, D.L., 2010. Alien species in freshwater: ecological effects, interactions with other stressors, and prospects for the future. Freshw. Biol. 55, 152-174.

Trometer, E.S., Busch, W.D.N., 1999. Changes in age-0 fish growth and abundance following the introduction of zebra mussels Dreissena polymorpha in the western basin of Lake Erie. North Am. J. Fish. Manag. 19, 604-609.

Vaughn, C.C., Hakenkamp, C.C., 2001. The functional role of burrowing bivalves in freshwater ecosystems. Freshw. Biol. 46, 1431-1446.

Ward, J.M., Ricciardi, A., 2007. Impacts of Dreissena invasions on benthic macroinvertebrate communities: a meta-analysis. Divers. Distribut. 13, 155-165.

Wright, J.T., Byers, J.E., Koukoumaftsis, L.P., 2012. Differences in anti-predator traits of a native bivalve following invasion by a habitat-forming seaweed. Mar. Freshw. Res. 63, 246-250.

Werner, S., Rothhaupt, K.O., 2007. Effects of the invasive bivalve Corbicula fluminea on settling juveniles and other benthic taxa. J. North Am. Benthol. Soc. 26, 673680.

Zaiko, A., Daunys, D., Olenin, S., 2009. Habitat engineering by the invasive zebra mussel Dreissena polymorpha (Pallas) in a boreal coastal lagoon: impact on biodiversity. Helool, Mar. Res, 63, 85-94. 